University of Louisville

ThinkIR: The University of Louisville's Institutional Repository

Electronic Theses and Dissertations

$5-1951$

\title{
An experimental study of the effect of five variables on the rate of reversal of reversible figures.
}

Clarence Howard Amster

University of Louisville

Follow this and additional works at: https://ir.library.louisville.edu/etd

Part of the Psychology Commons

\section{Recommended Citation}

Amster, Clarence Howard, "An experimental study of the effect of five variables on the rate of reversal of reversible figures." (1951). Electronic Theses and Dissertations. Paper 38.

https://doi.org/10.18297/etd/38

This Master's Thesis is brought to you for free and open access by ThinkIR: The University of Louisville's Institutional Repository. It has been accepted for inclusion in Electronic Theses and Dissertations by an authorized administrator of ThinkIR: The University of Louisville's Institutional Repository. This title appears here courtesy of the author, who has retained all other copyrights. For more information, please contact thinkir@louisville.edu. 
NAME OF SIUDENI: CLARENCE H. AMSIER

\section{TIPIE OH THESIS:}

An Experimental Study of the Effect of Five Variables on the Rate of Reversal of Reversible figures.

APPROVED BY READING COMMINTEE COMPOSED OH THE FOLLOWING MEMBERS:

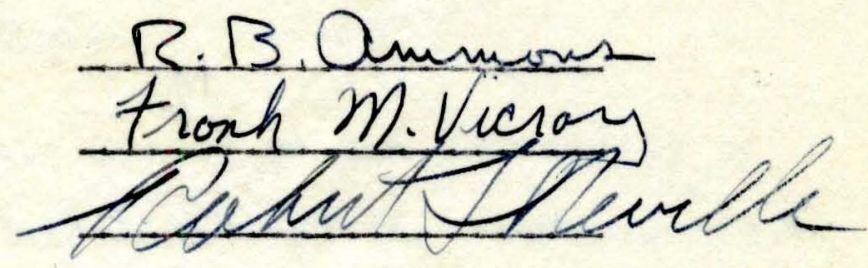

NAME OF DIPECTOR: R. B. Qumuons DATE: MAY, 1951 


\title{
AN EXPERTMENTAL STUDY OF THE EFPECT OF FIVE VARIABLES ON THE RATE OF REVERSAL OF REVERSIBLE FIGURES.
}

\author{
By \\ Clarence Howard Anster \\ B.S., University of Louisvilie \\ 1947
}

Submitted to the Graduate School of the University of Louisville in partial fulfillment of the requirements for the degree of Master of Arts.

Loulsville, Kentucky

1951 


\section{Acknowledgements}

The author of this experiment wishes to express his sincerest appreciation to the students of New Albany Senior High School, New Albany, Indiana who participated. in this experiment; Dr. Austin Cole, their principal, whose cooperation made the experiment possible; Charles Wells $\mathrm{Jr}$. , New Albany Public Schools' Director of Testing; who supplied the scores on The New California Mental Maturity Test; Joseph Spiegel, University of Louisville graduate student, who assisted in the statistical preparation; and Dr. R. B. Ammons, who guided the author in this study from the outset. 
Page

I. Introduction ........... I 1

II. Problem. . . . . . . . . . 5

Fig. I Schrbder Staircase....... 6

Fig. IA Beaunis Cubes........ ?

III. Procedure............ 9

Table I. Subject Number Assigned to Condition ........ 12

IV. Results.............. 16

Fig. 2. Effects of Different Instructions on Level of Performance. I7

Fig. 3. Effects of Different Drawings on Level of Performance... . 17

Fig. 4. Effect of Interpolated Activity on the Level of Performance . - 18

Fig. 5. Effect of Different Rest Periods Between Practice on the Level of Performance....... 18

Table II. Means of Reversal Scores for the Schroder Staircase and the Beaunis Cubes on Trials 6 to $15 \ldots 21$

V. Discussion.......... 26

VI. Summary and Conclusions........ 31 
Table of Contents

VII. Appendix

Table A. The Analysis of the Variance of the Number of Reversals on Reversibles Figures, on Trial 1.

Table B. The Analysis of the Variance of the Number of Reversals on Reversible Figures on Trial 1.

Table C. The Analysis of the Varfance of the Number of Reversals on Reversible Figures on Trials 6 to 15 .

Table D. The Analysis of the Variance of the Number of Reversals on Reversible Figures on Trials 6 to 15 .

Table E. The Analysis of the Variance of the Number of Reversals on Reversible Figures on Trial 6 to 15 .

Table F. Scores for 64 Subjects on 15 Trials. 
Introduction

Many conflicting reports have been given in the literature concerning the effect of various factors on the rate of reversal of figure and ground in reversible perspective.

Flugel $(7,8)$ suggested that changes in eye movement increased the number of reversals. He thought that fixation on one part of the figure could lead to $S^{i}$ s interpretation of this part as being "nearer" the observer and that changes in perspective were induced by changing the fixation point.

Donahue (5) found that there was a rhythm in the reversals but the shift in the fixation point was not in rhythm with the reversal. He suggested that "...the shifting appearance is due to central factors and that the eye movements depend upon the shifting appearance rather than vice versa..." (5, p. 616). The contention that eye movement caused the figures to fluctuate met a more vigorous blast from a later study. Higginson (13, p. 311), commented that "...the theory of eye-movements as constituting a determining factor... has not one single fact to serve as a scientific foundetion."

One investigator attempting to find an explanation for the phenomena of reversible Figure (5) doubted that a person's rate of reversals remained stable from one day to the next. Guilford and Braly's study (1i) attacked this question of reliability. They found that the rate of reversal was fairly constant for the same individual fron day to day. The reversals were especially consistent for the same individual throughout an hour of observation. 
The range of fluctuation rates among the various subjects was found to be quite high. Guilford and Braly inferred from this that the rate of fluctuation was a valid measure of some individual trait that is relatively constant. However, they could not rind anything to Which the rate of reversal was related.

Additional attempts have made to ferret out factors to which the rate of reversal are related. Many investigators have studied the relationship between the rate of reversals and biological functlonings. Two investigators $(23,3)$ found a relation between the rate of reversal and the fluctuation found in vaso-motor changes. McDougall (19) performed an experiment in which he produced fatigue in his subjects. Fatigue appeared to lengthen the time between reversals. It was inferred from this that fatigue raises the resistance in the nervous paths and this results in slow reversals.

McDougall (18) elaborated on his theory that raising the resistance in the nervous paths resulted in slow reversals. He contended that traits of personality are related to the speed of the nervous impulses in the nervous system. On the basis of this assumption an attempt was made to discriminate between an "introverted" and an "extroverted" personality by administering reversible figure tests. Other research workers $(16,12,11,1,21)$ have found supporting and conflicting evidence that "organic" and "functional" cases may be discriminated from "normals" in terms of their performance on reversing figures. Hunt states (16, p. 992) that "... although these few studies give no systematic picture of the receptive process in either 'functional' 'psychoses' or the various 'organic' conditions it appears tentatively that the perceptual processes show greater evidence of a deficit. Furthermore, the deficit appears to 
reside in the central processes initiated by receptor action, particularly in the response to patterns and the alteration of sets or attitudes."

Some psychologists have proceeded to investigate factors determining the rate of fluctuation by exploring the effect of existing conditions during testing. Gordon (10) believed that the rate of reversal might be affected by the nature of the task or stimuli. She administered different figures of varying complexity and found that a book figure changed more rapidly than the Schroder stairs figure. She inferred from this that complexity of the figure tends to make the rate of fluctuation slower.

Donahue (5) also conducted an experiment to find out if there was a difference in the fluctuation rate that might be attributed to complexity of the stimuli. His results in this respect were inconclusive, but he expressed the opinion that familiarity increased the rate of fluctuation.

The hypothesis that familiarity nor previous knowledge of the figure influences the rate of reversal has been supported by findings in other studies $(17,24)$. Washburn (2f, p. 638) states that her "results strongly suggest that the ease or difficulty of so-called. voluntary control of the perceptual interpretations of these figures rests on two principles: (1) the simplicity or complexity of the response suggested, and (2) its frequency in ordinary life."

The implication of the previously mentioned studies that fluctuational rate might increase with practice is supported by several experiments $(4,5,14,17)$. Kbhler's results (17) agreed with the findings of the other experiments cited, but he offered a physiological explanation of the results. He told two subjects to "keep" whatever figure they saw. They were given the task of observing a reversible 
figure(Fubin Disk)until it fluctuated five times. Although the subjects were told. to hold the figure it fluctuated nore rapidly as the length of time of observation increased. The subjects were given one minute rest between trials so that the reversals would. not become less "orderly" with prolonged observations. Kothler (17, p.72) inferred. from this that "... a figure process seens to have some effect by which it tends to more and more block its ow way." He proposes from this that the phenomena of rate of reversal may be assoclated with changes in electrical currents in the nervous system. Other investigators $(7,4,15,17)$ proposed that a "set" or an "attitude" might produce differences in the rate of fluctuations. Bruner, Postman and Mosteller (4) told $I / 3$ of his subjects to hold the figure, as Kdhler had. They also told $1 / 3$ of the Ss to reverse the figure fast and the other $1 / 3$ to try to let it reverse "naturally." The individuals that were told to alternate the figure, reversed the figure much faster than those who were told to "hold." the figure. The investigator also found. that interaction between subjects and set resulted in a wide range of differences. 


\section{II.}

Problem

Various studies that have been presented previously report conflicting evidence as to the effect of various conditions on the rate of reversal of "reversible figures."

One of the purposes of this study is to test the following hypotheses:

I. There is no significant difference between the reported rate of reversal of the Schrbder staircase and the Beaunis cubes for males and the reported rate for females. (Figures on next page).

2. There is no significant difference between the reported rate of reversal of the Schrdier staircase and the Beaunis cubes of subjects who were told to try to keep the figure from changing and the subjects who were told to try to make the figure change rapialy.

3. There is no significant difference between the reported rate of reversal of subjects who were shown the Schrdder staircase from the reported rate of reversal of subjects who were shown the Beaunis cubes.

4. There is no significant difference between the reported rate of reversal of the Schrdder staircase and the Beaunis cubes for: (a)- subjects who were given no rest between trials; (b)- subjects who were given 60 seconds rest between trials; and (d) - subjects who were given 180 seconds rest. 
Figure 1.

Schrdder Staircase 


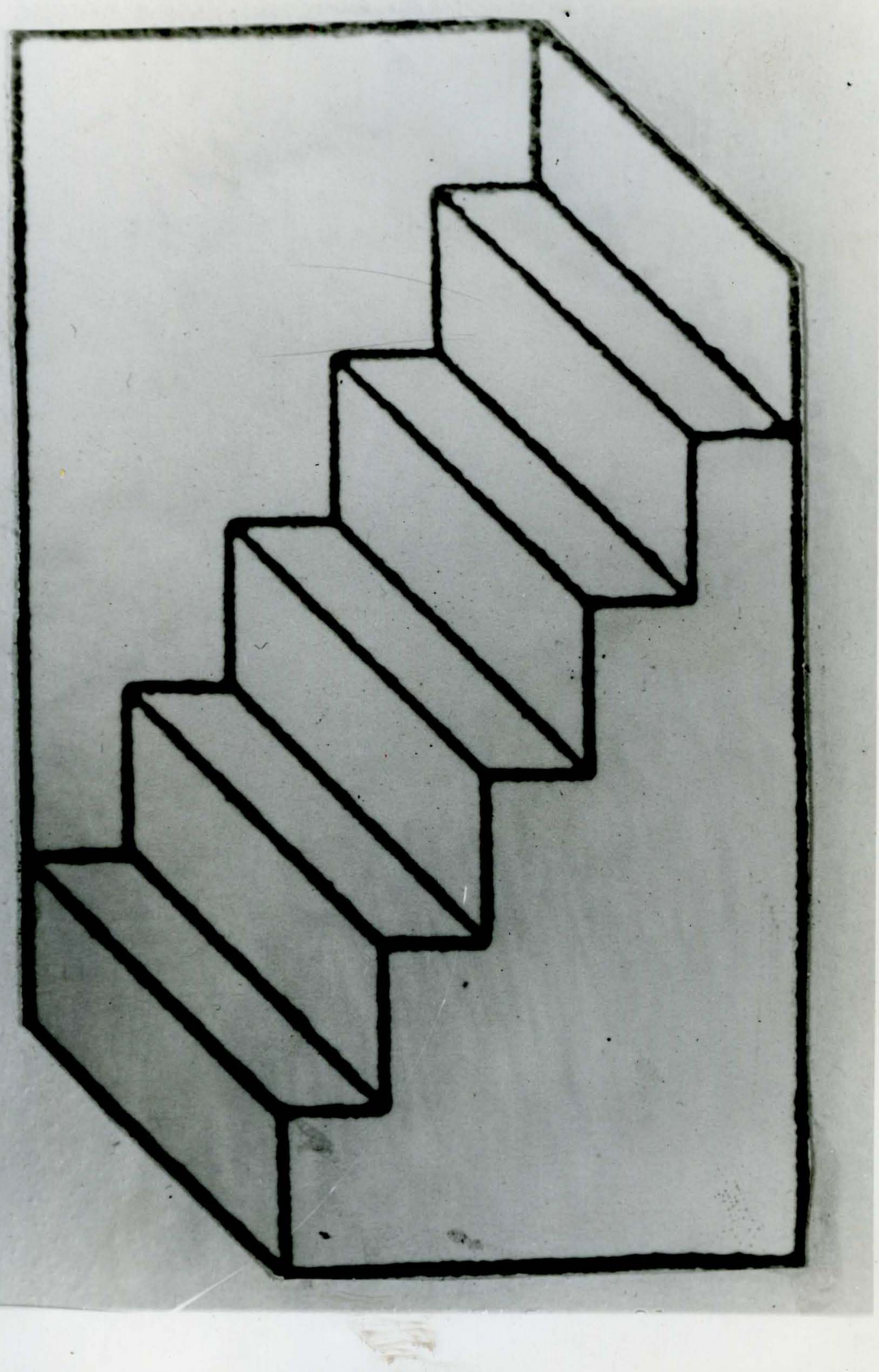


Figure I-A.

Beaunis Cubes 


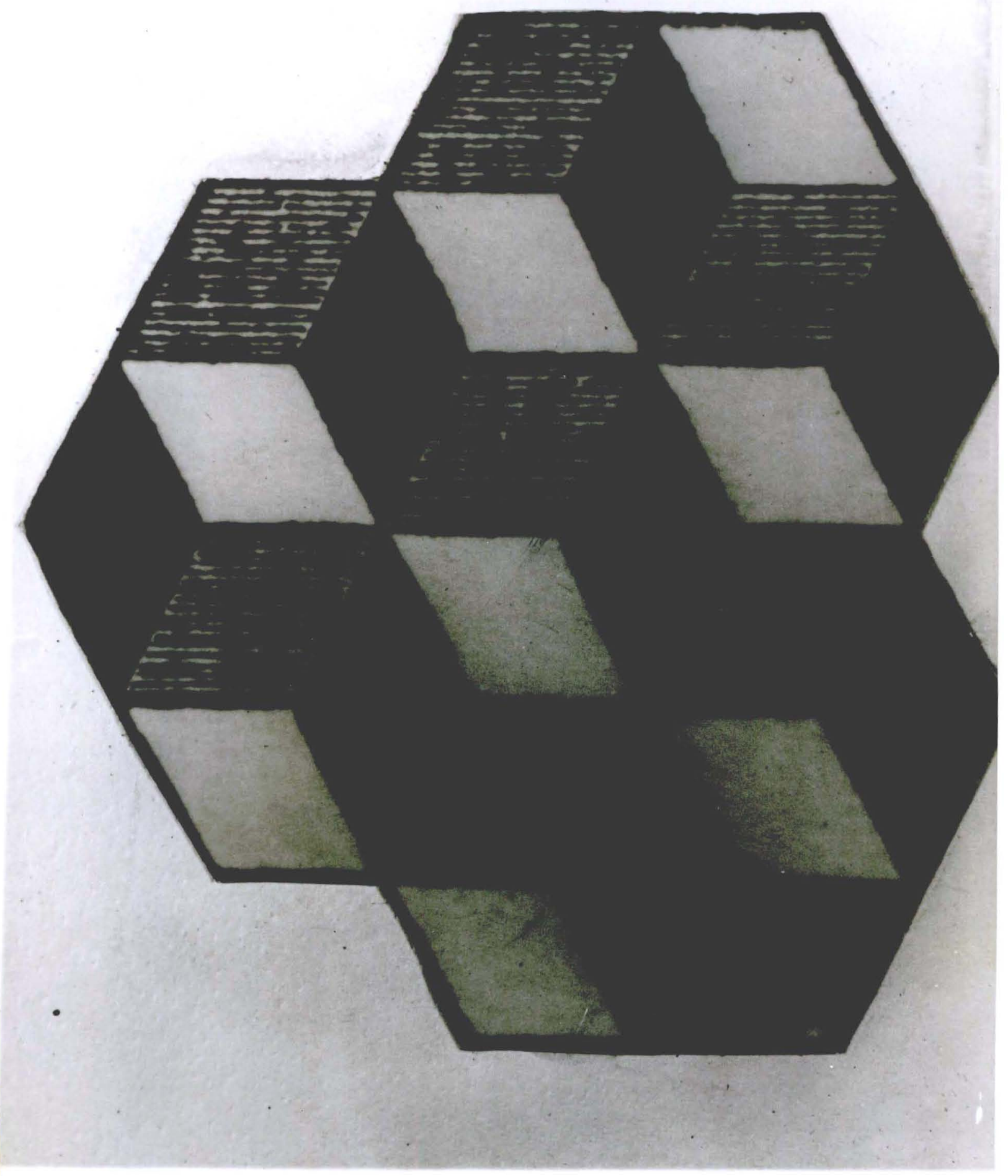




\section{between trials.}

5. There is no significant difference between the reported rate of reversal of the Schrbder staircase and the Beaunis cubes of subjects who were given another perceptual task between trials and the rate of reversal of subjects who were not given such a task between trials.

Some of the investigators have hypothesized that the rate of fluctuation of reversible figures may be used to discriminate between "nornal" people and "functional" and "organic" cases. It is also a purpose of this study to accurulate information on the performance of a "normative" group to give a criterion for a later investigation of the fluctuations reported by "organic" and "functional" cases who are given the task of observing reversible figures.

Another purpose of this study is to find if there is a relationship between the intelligence of an inaividual (as measured by the New California Short-Form Test of Mental Maturity Intermediate $147 \mathrm{~S}-$ Form) and the individual's rate of reversing figures. 
III.

Procedure

Subjects

Sixty-eight Ss were selected at random from New Albany High School students (at New AIbany, Indiana) attending "study hall periods" from 9:00 a.m. to $2: 45 \mathrm{p} . \mathrm{m}$. during the school week. Only two males and one female, of the 68 students sclected, refused to participate in the experiment. Sixty-five students, 33 males and 32 females participated in the experiment. One male was dropped. from the study, for reasons that are explained under the experimental procedure.

Each of the 32 males and 32 females that were retained in the experiment was assigned to one of the 64 experimental conditions. The S' ${ }^{\prime}$ ages ranged from 16 years, 1 month to 20 years, 2 months.

Meterials

A 12 in. $x 16$ in. $x 24$ in. box painted dull black inside and outside with a 10 in. $x 10$ in. opening contained a halfsilvered mirror was mounted at the eye level of the sitting $s$. The mirror was masked to allow a 3 in. $x 3$ in. opening for observation. A rack for two 3 in. $\times 4$ in. reversible figured on 10 in. $x 10 \mathrm{in}$. dull white cards was mounted $24 \mathrm{in}$. behind the one-way mirror.

The Schrbder staircase (Fig. I, $p, 7$ ) and the Beannis cubes (Fig. 2, p. 9) were used as the reversible figures. A "I50-watt G. E. reflector flood Iight" was fixed inside the box so that the 


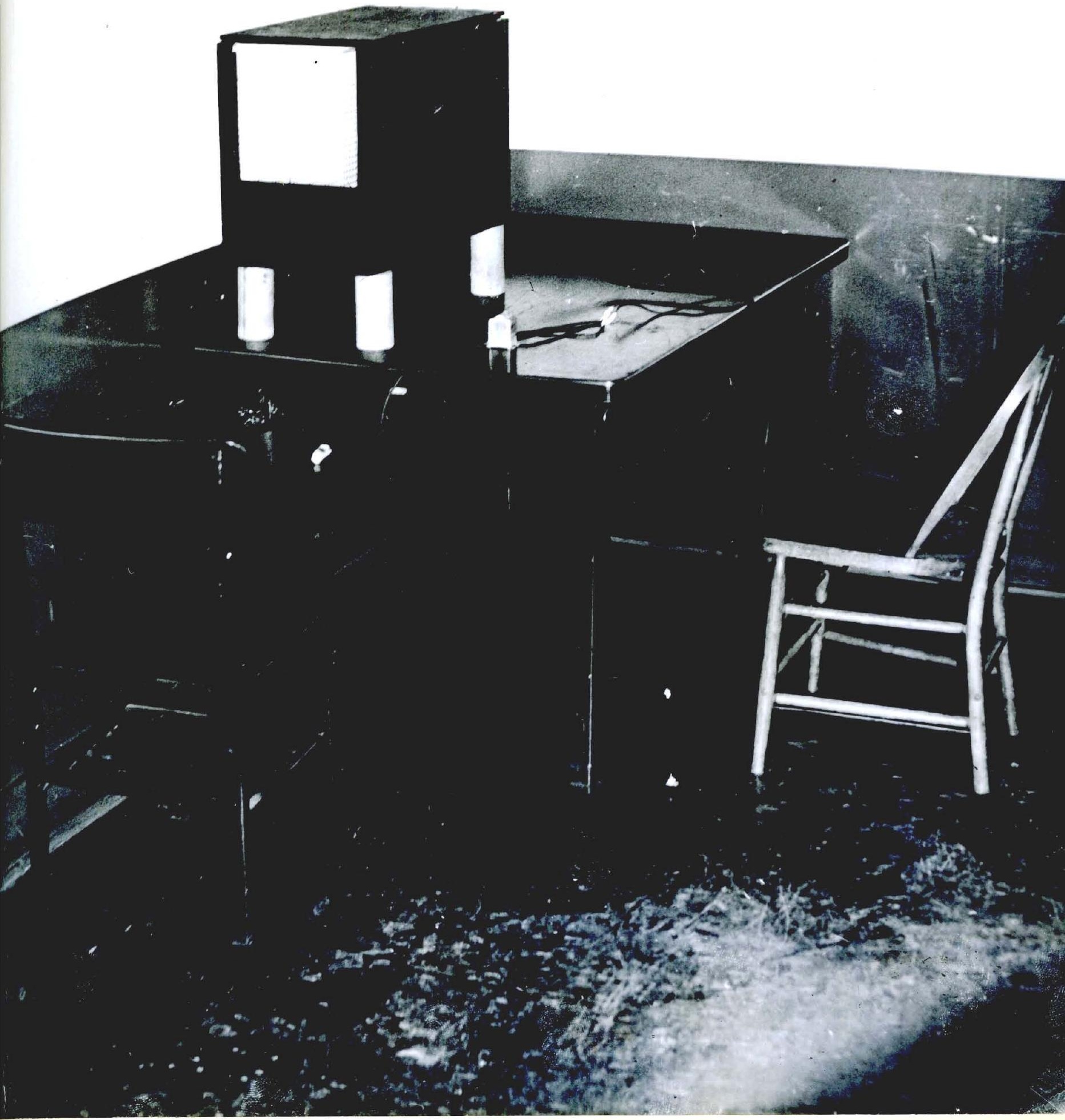


cards were illuminated without glare or shadows.

The experimenter was provided with a switch to control the light. The subject was provided with a microswitch, which in turn was wired to a 115-volt electrical counter. (A circuit drawing for the apparatus will be found in the appendix).

The trial periods and the rest periods were timed with a stop watch.

The apparatus was operated as follows: The figure assigned to $S$ was placed in the rack. E switched on the light for the trial period and then switched it off. During the period the $\mathrm{S}$ could see the figure, he recorded each reversal by pressing the microswitch.

\section{Experimental Procedure}

The apparatus was set up so that the opening for viewing the drawing was at eye level. A chair was placed three feet to the right rear of $S^{\prime} s$ chair. A given $S$ was selected at random from the group attending the "study halI" that hour and was randomly assigned to one of the 64 conditions. The 64 conditions were combinations of five variables and the condition of those five variables that may be schematized as follows:

Rest between one-minute trials-

1. None

2. 20 seconds

3. 60 seconds

4. 180 seconds.

Sex -

1. Male

2. Female 
Figures-

1. Schrbder staircase

2. Beaunis cubes

Set-

1. Rapid

2. Hold.

Interpolated Activity

1. None

2. Write alphabet upside down and backwards. (Table I, (next page) presents the condition to which each subject was assigned.

$S$ was given the one of four instructions that was appropriate to the assigned condition. The four instructions follow:

1. (Conditions - Hold perspective: Interpolated Activity) "When I turn on a light inside the box you will see a drawing. You look at it steadily and 1t will probabiy change perspective. (Show example). Here is a button that you will push every time the whole figure changes. (Try it). I want you to try to keep from changing the figure but push the button when it does. After a certain amount of time I will turn off the light inside and you will start writing the alphabet upside down and backwards. (Try it). When I say "ready" you stop immediately and prepare to look at the figure again and I will turn on the light. We will continue this until I tell you when we are finished. Please do not talk while looking at figure. Remember now, push the button only when 


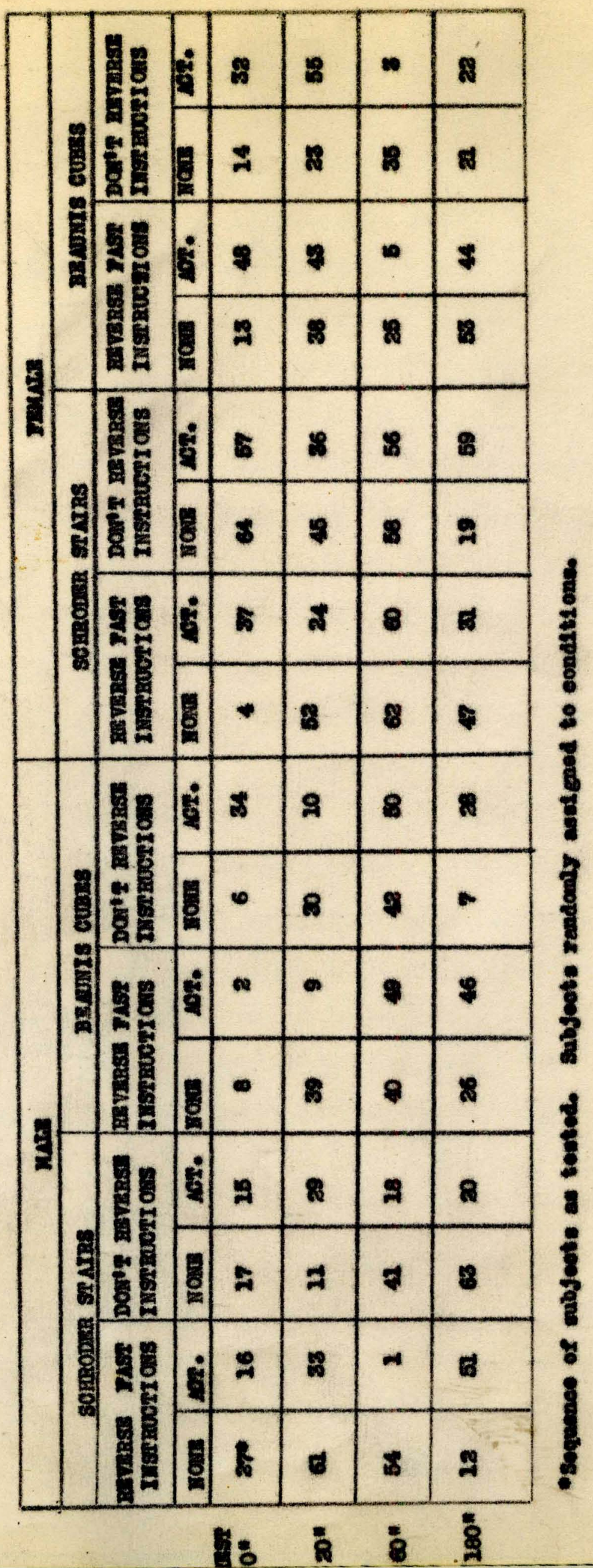


the whole figure changes and try to keep it from changing." 2. (Conditions - Change rapidly; Interpolated Activity)

"When I turn on a light inside the box you will see a drawing. You look at it steadily and it will probably change perspective. (Show example). Here is a button that you will push every tine the whole rigure changes. (Try it). I want you to try to change the perspective of the whole figure as fest as you can but don't push the button until you see the whole figure definitely change. After a certain amount of time I will turn off the light inside and you will start writing the alphabet upside down and backwards. (Try it). When I Say "ready" you stop imnediately and prepare to look at the figure again and I will turn a light. We will continue this until I toll you when we are finished. Please do not talk while looking at the figure. Remember now, push the button only when the whole figure changes and try to make the figure change rapidiy.

3. (Conditions - Hold perspective; No Activity)

"When I turn on a light inside the interpolated box you see a drawing. You look at it steadily and it will probably change perspective. (Show example). Here is a button that you will push every time the whole figure changes. (Try it). I want you to try to keep from changing the figure but push the button when it does.

After a certain amount of time I will turn off the light inside and you will relax and close your eyes. When I say "ready" you prepare to look at the drawing again and I wiIl turn on the light. We will continue this until I will tell you when we are finished. Please do not talk while looking 
at the figure. Remember now, push the button only when the whole figure changes and try to keep it from changing.

4. (Conditions - Chenge rapidly; No activity)

"When I turn a light inside the box you will see a drawing. You look at it steadily and it will probably change perspective. (Show example). Here is a button that you will push every time the whole figure changes. (Try it). I want you to change the perspective of the whole figure as fast as you can but don't push the button until you see the whole figure definitely change. After a certain amount of time I will turn off the light inside and you will relax and close your eyes. When I say "ready" you prepare to look at the drawing again and I will turn on the light. We will continue this until I will tell you when we are finished.

Please do not talk while looking at the figure. Remember now, push the button only when the whole figure changes and try to make the figure change rapiciy.

The figure that was not assigned to the $\mathrm{S}$ was shown to him until $E$ was satisfied that $S$ saw a reversal. After the instructions were given $\mathrm{E}$ turned on the light inside the box so that $\mathrm{S}$ could see the drawing for one minute. 3 pushed a microswitch each time the figure reversed for him.

At the end of the minute the light was turned off and E recorded the number of reversals in a manner that could not be seen by $S$. The number of reversals for each subject on each trial is in Table $\mathrm{E}$. (See Appendix). 
$S$ was then allowed the appropriate rest condition. $\mathbb{E}$ gave a ready signal three seconds before the next trial was to start. After ten trials, $2.1 \mathrm{Ss}$ were given five minutes to do anything they wanted to. The Ss were then given five more trials. After the last trial $S$ was asked what happened while he looked at the figure. The drawing was removed from the box and $S$ was asked to show or explain when he saw when the figure reversed. The record of one $S$ was omitted from the study because he stated in the inquiry that "I did not understand that I was supposed to push the button every time the figure changed until the thiro. trial." A rapid increase in the recorded fluctuations on the third trial corroborated his statement.

All the rest of the Ss indicated in the inquiry that they had seen the correct percept. 


\section{IV.}

Results

The mean performance of the Ss who were instructed to "hold" and performance of those who were instructed to "reverse rapidy" are shown in Fig. 2.

The performance curve (Fig. 2, p.17) of the Ss who were told to "reverse rapidly" is negatively accelerated throughou.t. The performance is much higher than the performance of those who were told to "hold" the figure. The performance of the Ss told to "hold" the figure increases in the first three trials but it stabilizes at a low level for the remainder of the trials.

It appears in Fig. 3 (p. 17) that the performance on reversing the Schrdder stair case is much higher than the performance on reversing the Beaunis cubes. The rate of reversal increases throughout the trials on the staircase with the exception of trial 12. There is some increase in the perfomance on the staircase after the rest period. The performance on the Beaunis cubes increases until the fifth trial. It becomes more stable there and the performance remains about the same for the remaining trials.

Surprisingly enough, Fig. $4(p .18)$ shows that the performance of those Ss who had interpolated activity is better than that of those who did. not have any interpolated activity. The level of performance under both conditions increased throughout practice. Both curves increase slightly after the five minute rest period.

It may be observed from Fig.5 (p.18) that the Ss who had 180 seconds rest, performed considerably better than those in the other rest groups.

One of the most thought provoking elements on this graph is the performance of the Ss with 60 seconds rest. The performance levels 


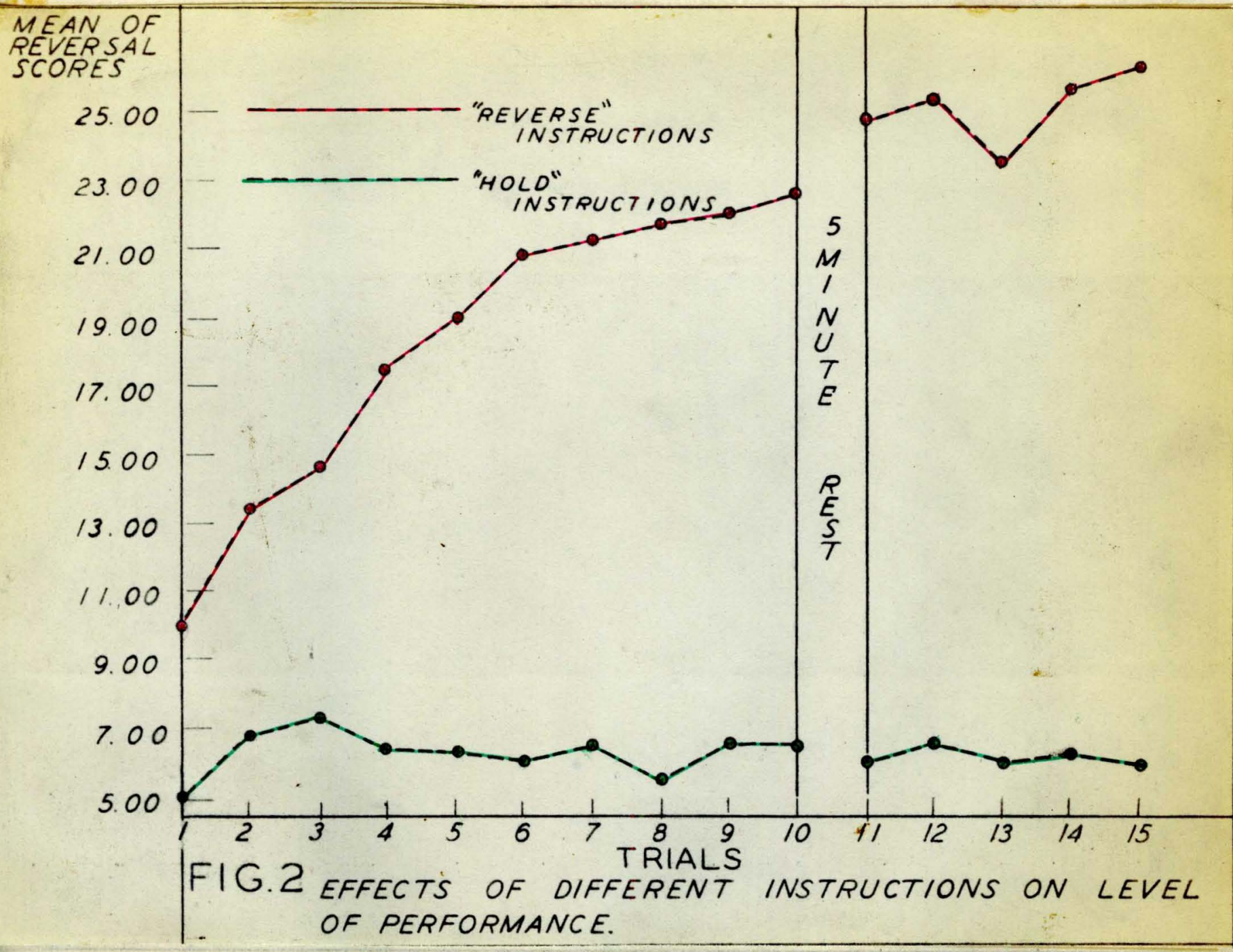




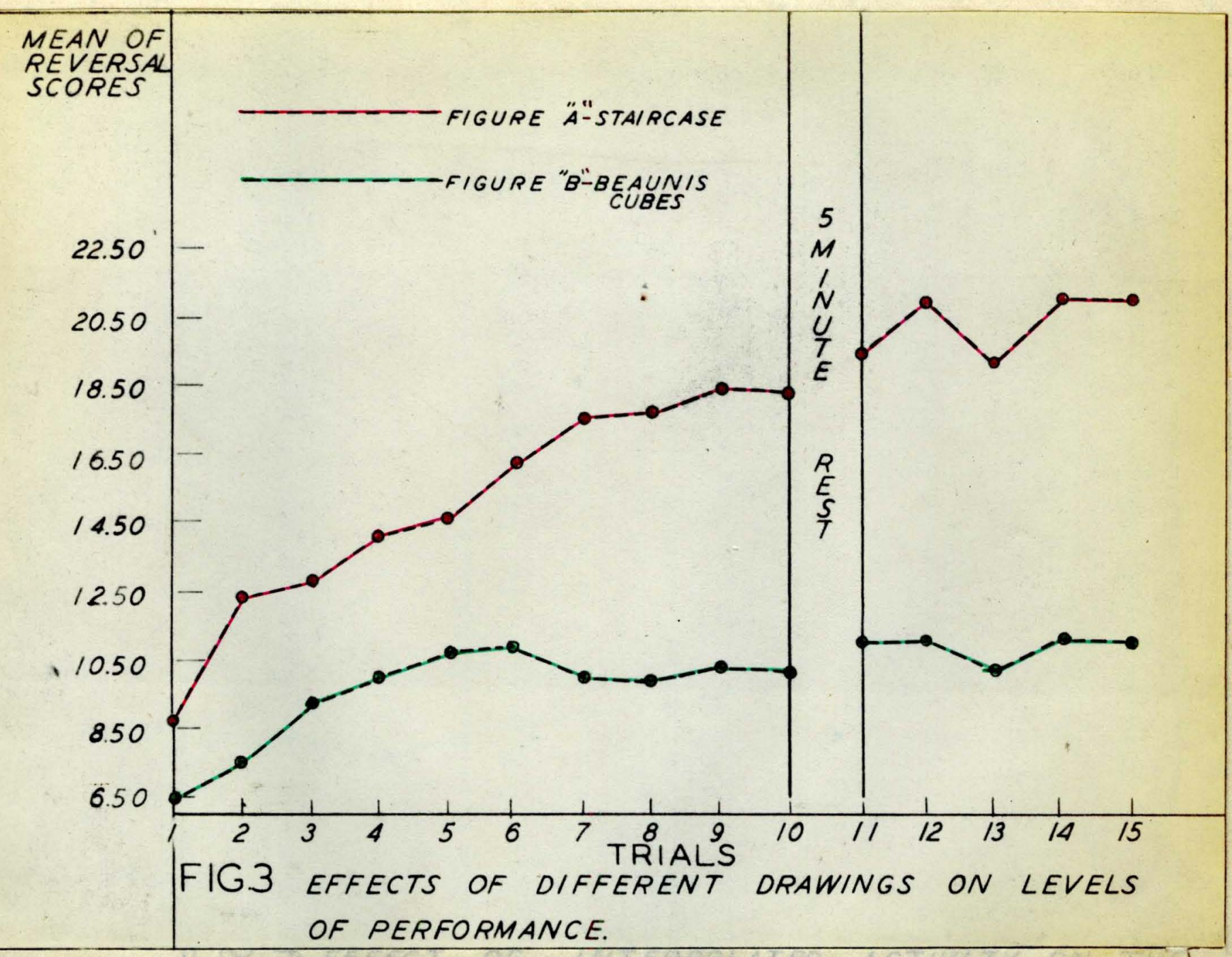




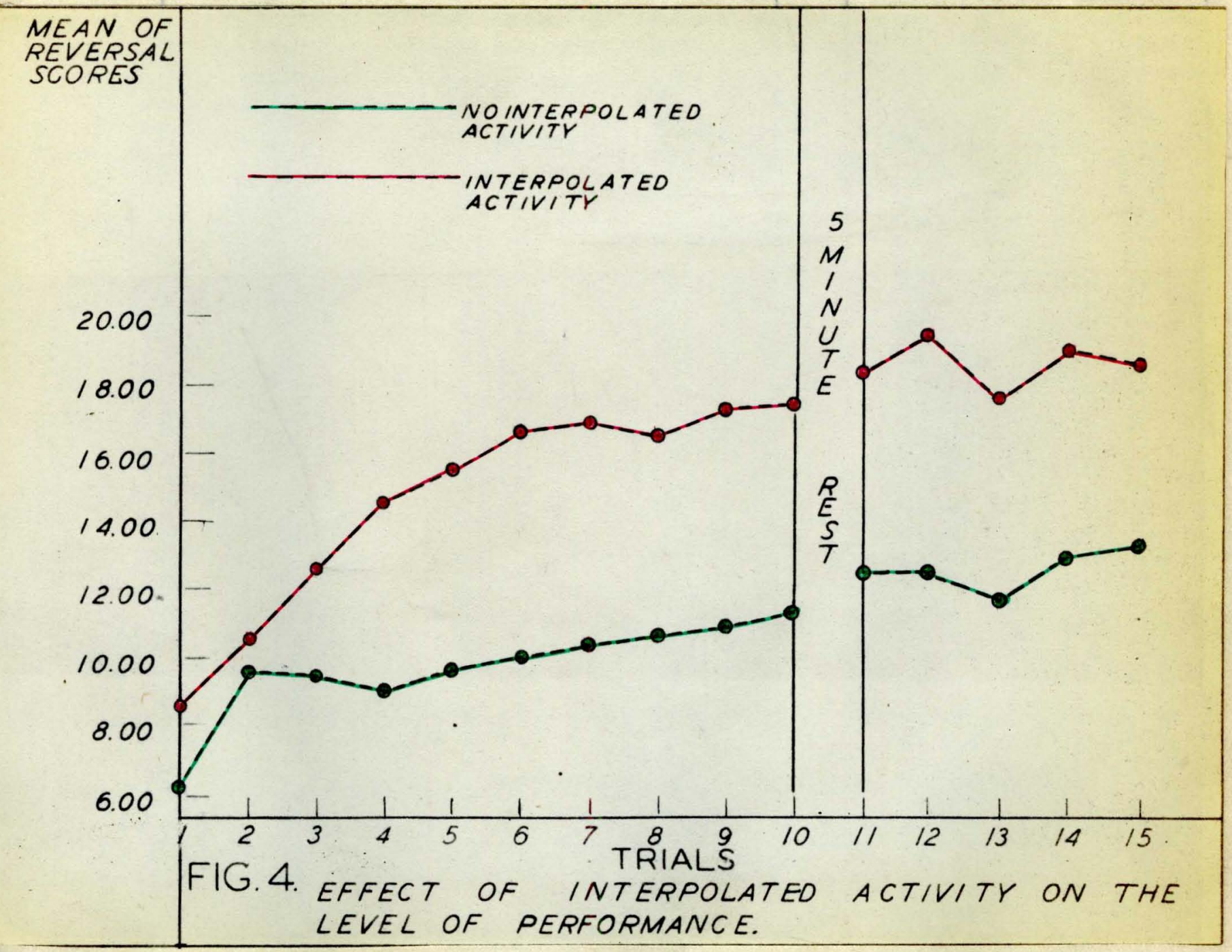




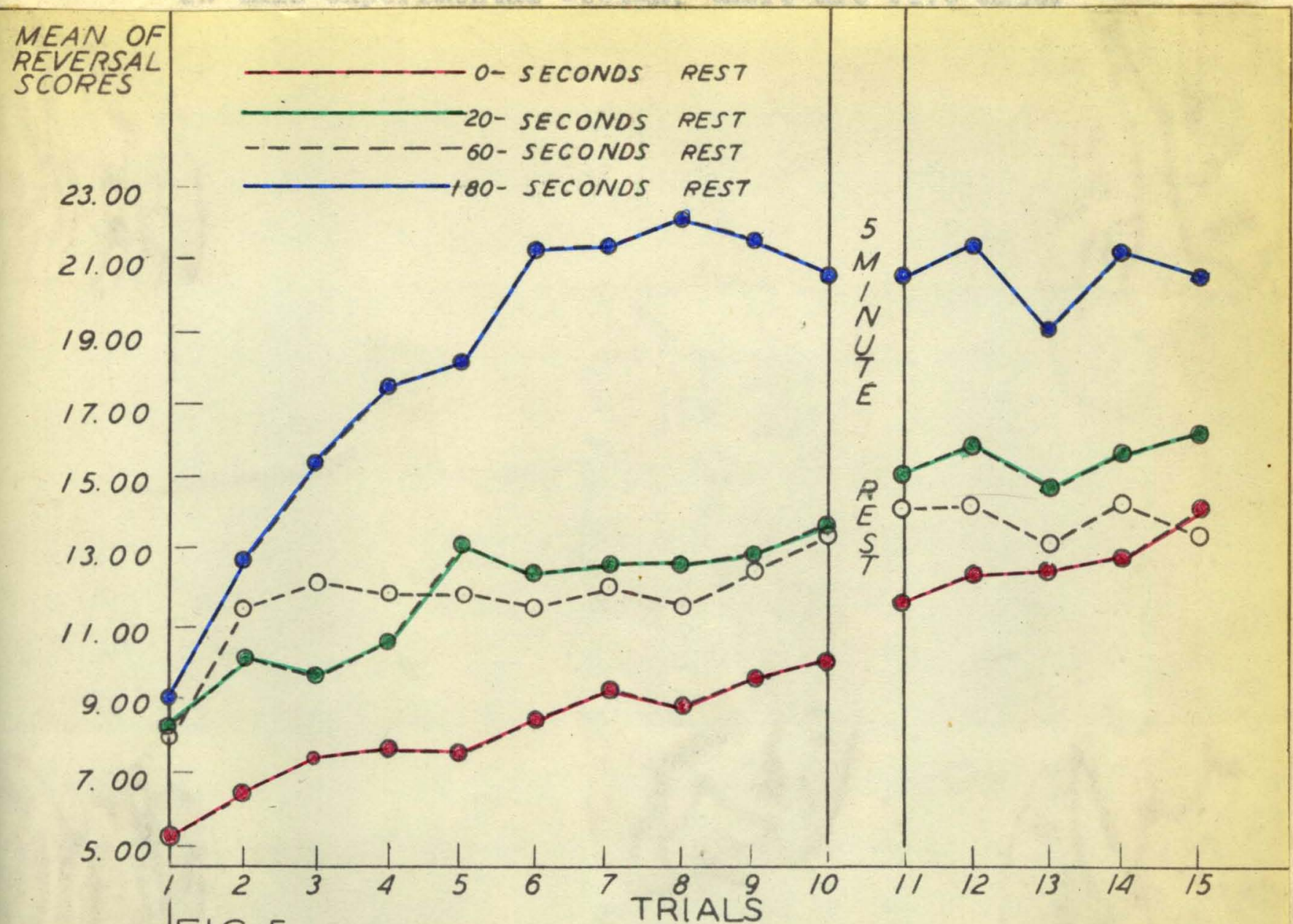

FIG.5 EFFECTS OF DIFFERENT REST PERIODS BETWEEN PRACTICE ON THE LEVEL OF PERFORMANCE 
off after the second trial and remains about the same throughout the rest of the trials.

Statistical Analysis

In this experimental design, there are five major variables. Four of the variables are varied in two ways and the fifth is varied four ways. It can be observed (see Table 1) p. 12 that a $2 \times 2 \times 2 x 2 x \leq$ factorial design without replication, as descrtbed by Edward.s (5) was used.

The analysis of variance was made on scores obtained on the first trial and trials 6-15. (See Appendix, Tables A,B,C, $D$, and $E$ ).

Using the pooled mean square of the higher order interaction as the error term and eliminating the mean square of those factors that are significant, the effects of the major variables were then tested. The eliminated higher order interactions that were significant were used as the error terns so to test each variable within that interaction. (See Appendix-Tables $B, D, E$ ).

Analysis of variance of trial 1 as shown in Table A gave the following results: The interaction of Sex $X$ Drawing $X$ Instructions on the first trial was found to be significant beyond the I percent level. Using the sumnation of the mean squares of the higher order interactions as the error term, the variable "set" is significant at the I percent level. Using the higher order interaction mean square ( Sex X Drawing $\mathrm{X}$ Instructions) as the error term for variables within that interaction, revealed 
none of them to have significance.

Utilizing the method described above to test the significance of variables on trials six through fifteen, (See Appendix Table $C$ ) we found the following four variables significant at:

1. The I\% levels;

a. Sex X Rest X Instructions.

b. Drawings $\mathrm{X}$ Instructions.

c. Activities,

d. Drawings.

2. At the $5 \%$ Ievel;

a. Rest

Using the higher order interaction mean square (Sex $\mathrm{X}$ Rest $X$ Drawing $X$ Instructions) as the error term, for variables within that interaction, revealed that the Instructions had an effect significant at the 5 per cent level.

Using the mean square of Drawings $X$ Instructions as the error term, for variables within that interaction, revealed none of them to have significance.

The significant interaction of Drawings $X$ Instructions indicates a differential in the rate of reversal on the staircase and the cubes when given the instructions to reverse "rapidly" or "hold". This is clearly shown in Table 2. 
Table 2. Means of Reversal Scores for the Schrbder Staircase and the Beaunis Cubes on Trials 6 to 15.

Instructions

$\frac{\text { Drawings }}{\text { Stairs Cubes }}$

Reverse "Rapidly"

"Hold"

Difference

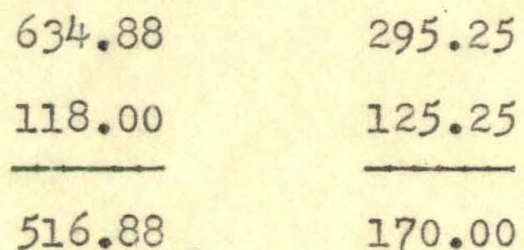

339.63

7.25

332.38 
The difference between the rate of reversals on the stalrcase with "rapid" set and the staircase with the "hold" set is equal to 516.88. The difference between reversals on the cubes with a "rapid" set and the cubes with a "hold" set is 170.00 . Obviously, the discrepancy in the rate of reversals between a "rapid" set and a "hold" set is greater when the stalrcase drawing is presented. than when the Beaunis cubes drawing is presented. It may also be observed that the difference in the reversal rate on the staircase when the "rapid" set is given and the cubes when the "rapid" set is given is equal to 339.63. The difference between the staircase when the "hold" set is given and the cubes when the "hold" set is given is equal to 7.25. It is apparent here also that the discrepancy in the rate of reversals between the staircase and the Beaunis cubes when the "rapid". set is given is greater than when the "hold" set is given.

A rank order correlation was computed between the sum of scores for trials six through ten and the sum of scores for trials eleven through fifteen, to estimate the reliability of the scores. A correlation of $.92-.019$ was found.

A rank order correlation was also computed between the sum of scores on trials six through fifteen and the scores on the NonLanguage factors (New California Short Test of Mental Maturity) and the Language factors. The correlation with Non-Language factors was .03t .13 and the correlation with Language factors was -.004 \pm .13 . 
Introspective Reports of the Ss

The author took notes on $\mathrm{SS}^{\prime}$ comments during the test and questioned further after the tests. Some of the reports that seem to be significant and the conditions given to the subject are as follows:

Figure Set Rest Activity

Stairs Fast $0 \quad 0$ "The Iines in the second or third. step from the top started fading. Looking at the top step and then bottom made it move." (A frequent response).

Stairs Fast 0 o "At first the steps looked like an accordion."

Stairs Slow $0 \quad 0$ "I just can't keep it from changing." Blocks Fast $0 \quad 0$ "Blocks faded and looked like steps towards the last." "Easier to change when blinked." "(Faded?)", "Looked like black blocks faded out and. white stayed diagonalıy."

Stairs Slow $0 \quad 0 \quad$ (E-Reversed by two's with long interval in between)

"Blinking seemed to make it move." (A frequent response).

Stairs Fast 20" 0 "Click of the counter made it change. Steps formed a solid sheet of lines towards the end." 
Figure Set Rest Activity

Stairs Fast 20" Yes "After looking at it quite awhile the middle looked like an accordion."

Bloclss Fast 20" 0 "Blinking and moving my head helped change it."

Blocks Hold 20" Yes "When I concentrated on it it didn't seem to change."

Stairs Fast $60^{\prime \prime} 0$ "(S-moved head to make change.) Trial 8- The Ionger I look at it the Iess $1 t$ wants to change."

Blocks Slow 60" Yes "Everytime I bat my eyes it changes." (S-Pushing button when not blinking). Stairs SIow 60" 0 "Is it that thing changing or is it the way I look at it?"

Stairs Fast 180" 0 "...the Iines seem to fade out." Blocks Fast 180" Yes "(Trial I0) Boy its getting harder to change now" (Trial 13) "I just can't get it to change." 
Summary of Introspective Reports

Most of the Ss attribute the drawings with the power of control over the process of reversing. They usually indicate that they can manipulate the process of reversing to some extent but the origin of the process or the process itself is unexplained. The Ss reported that various factors seemed to efrect the rate of reversal. They reported that reversing was effected by: (a) changing the fixation point (although they were told to look at the whole figure), (b) blinking, (c) clicking of the electric counter, (d) head movement and (e) "concentration". Many of the subjects reported that the figures became distorted as practice had continued. The Ss who were given the most massed practice (no rest) reported this most frequently. 
Discussion

\section{Limitations}

The data were gathered during school hours at New Albany High School, New Albany, Indiana. The testing required a considerable amount of S'' school time so the sample was limited to 64 to maintain the school's cooperation. There are 64 conditions in the design so the experiment was done without replication. If a larger sample had been obtained the results would have nore stable.

In the atterpt to ascertain whether the reported rate of reversal of the Schrbder staircase and the Beaunis cubes is related. to "Intelligence", the New California Short-Form Test of Mental Maturity was used as the criterion of "intelligence". It is possible that the New California Short-Form Test of Mental Maturity does not provide an adequate measure of S's intelligence.

A further limitation must be considered in the subjective approach to the demonstration of reversal before actual practice. The $E$ had to rely on the S's report that a reversal had occured. Steps to Account for Limitations

A larger sample, at least double in size, might be obtained so that replication of this experiment could be made. Also, the use of the Wechsler-Bellevue Intelligence scale, might prove worthwhile in attempting to further search for a relationship between reversal rate and individual intelligence, since it contains more performance items, such as the Block Design.

At this time, $E$ can not suggest how to eliminate the subjectivity of the initial measurements. 
Generalizations

From the results of this study we make the following suggestions:

1. There is no significant difference in male and female performance on reversible figures.

2. There is a significant difference in performance on Schroders staircase and the Beaunis cubes. The Beaunis cubes appear to be more complex as they have a greater area of lines (Shading, content of figure, and ground). Therefore the lower performance on Beaunis cubes seems to be a function of complexity of the reversible drawing.

3. There is a significantly higher performance on the task, when there is also interpolated perceptual activity between trials. This may result from the subjects maintaining an "attitude" or "set" that is supported by continued activity. Interuptions of activity or performance of the individual may inhibit a "set" directed to continued performance. Also the change of activity may minimize figural after effects.

4. Practice at the task of reversing figures seens to increase the level of performance like it does in other skills. It appears that the largest rate of increase occurs in the early trials.

5. It appears that distributed practice facilitates a higher level of performance than massed practice on the task of reversing figures. However, the difference in quantity of time between practice periods does not seem to cause a consistent relative difference in performance at the task.

6. The difference in the rate of reversal when the staircase is presented. with a "rapid" set and with a "hold" set is much more than the difference in the rate of reversales when the cubes 
are presented; also the difference between the rate of reversals of the staircase and the cubes is much more with a "rapid" set than that with a "hold" set. 
Implications

The evidence from this study indicates that the method of presenting reversible figures and the reversible figures themselves influence the rate of reversal. This suggests that standardized conditions and materials must be presented in any attempt to investigate the process of reversing figures or in any attempt to relate the rate of reversal to some individual trait.

The results of this study also reveal that Ss who are instructed to reverse figures "rapidly" perform at a significantly higher level than the Ss who are told to "hold" the figure. The Ss who were told to "hold" the figure did not demonstrate a positive increase in their rate of reversal like the Ss who were told to reverse "rapidly". This seems to indicate that "set" is related. to the rate of reversal. This evidence does not support Kbhler's observation. He found that two Ss increased their rate of reversal when they were told to "hold" the figure and concluded that the percept processes are associated with electric currents in the nervous system.

The evidence that a "set" is related to the level of performance on reversible figures may demonstrate the importance of a counselor's attitude in therapy. If the counselor communicates a negative "set", would the Ss activity be inhibited? It appears so. 
Suggestions for Further Study

The following studies have been suggested by this experiment:

1. Study the relationship of other drawings to the rate of reversal.

2. Study the effect of eye movement on the rate of reversal.

3. Find out if there is a relationship between the location of the fixation point and reversals.

4. Investigate the effect of a longer inter-trial rest interval.

5. Find out if the rate of reversal may be used to discriminate between "normal" people and "organic" brain damage cases.

6. Conduct an experiment to see whether reversals can be conditioned to outside movement or noises.

7. Repeat this experiment with replication. 


\section{VI. \\ SUMMARY AND CONCLUSIONS}

This study was made to investigate the effect of five variables on the reported rate of reversal of the Schrdaer staircase and the Beaunis Cubes.

The five variables and the condition of those five variables between one-minute tralals were:

$$
\begin{aligned}
& \text { Rest - } \text {.. None } \\
& \text { 2. } 20 \text { Seconds } \\
& \text { 3. } 60 \text { Seconds } \\
& \text { 4. } 180 \text { Seconds } \\
& \text { Sex - 1. Male } \\
& \text { 2. Female }
\end{aligned}
$$

Figures - 1. Schröder staircase

2. Beaunis cubes

Set (instructions) - 1. Rapid.

$$
\text { 2. Hold }
$$

Interpolated activity - 1. None

2. Write alphabet upsice down and backwards.

Sixth-four subjects were assigned to the sixty-four possible combinations of the conditions of the five variables, and observed for 15 one-minute periods.

Five hypotheses were tested:

1. There is no significant difference between the reported rate of reversal for males and the reported rate for females. 
2. There is no significant difference between the reported rate of reversal of Ss who were told to try to keep the figure from changing and of Ss who were told to try to make the figure change rapidiy.

3. There is no significant difference between the reported rate of reversal of $\mathrm{S}_{\mathrm{S}}$ who were shown the Schroder stalrcase from the reported rate of reversal of subjects who were shown the Beaunis cubes.

4. There is no significant difference between the reported rate of reversals for: (a) Ss who were given 0 rest between trials; (b) Ss who were given 20 seconds rest between trials; (c) Ss who were given 60 seconds rest between trials; and (d) Ss who were given 180 seconds rest between trials.

5. There is no significant difference between the reported rate of reversal of $\mathrm{Ss}$ who were given a task between trials and the rate of reversal of subjects who were not given a task between trials.

6. A set to reverse figures "rapidly" appears to result in greater differences in the rate of reversal than when a "hold" set is presented.

7. When the Schrdder staircase is presented with a "rapid" set and with a "hold" set, the difference in the rate of reversal is greater than the difference in the rate of reversals when the Beaunis cubes are presented.

The evidence from this study:

1. Supports the first hypothesis.

2. Does not support hypothesis $2,3,4$ or 5 . 
This study also attempted to find out if the rate of reversals of reversible figures was related to intelligence.

Stat No appreciable correlation was found between the rate of reversal of the figures, and the intelligence of the subject, as measured by the New Califofnia Short-Form Test of Mental Maturity.

The following conclusions seem warranted:

1. There is no significant difference between malo and female performance on reversing figures.

$\sigma$ mit 2 . When Ss in this study were instructed to accelerate their 7. pllowing perfornence they apparently did.

3. Ss in this study seemed to find the Schrbder staircase more easily reversible.

4. Rest was a significant factor in this study with Ss responding better after rest than after no rest.

5. Interpolated activity seemed to be conducive to more rapid. reversals. 
VII.

APPENDIX 
Table A. The Analysis of the Variance of the Number of Revergals on Reversibles Figures, on Trial 1.

Error Term* (Pooled Higher) Order Interaction

$S X R X I X D X A$

$+R X I X D X A$

$+S X R X I X A$

$+S \times R \times D X A$

+ SX DXIXA

- SXRXDXI

$+D X I X A$

$+\mathrm{RXIXA}$

$+\mathrm{RXDXA}$

+ RX D X I

$+S X I X A$

$+S X D X A$

+ $S \times R X A$

$+5 \mathrm{X} X I$

$+S \times R X D$

+ IXA

$+\mathrm{DXA}$

\begin{tabular}{|c|c|c|c|c|c|}
\hline $\begin{array}{l}\text { Sum } \\
\text { of } \\
\text { Squares }\end{array}$ & Df. & $\begin{array}{l}\text { Mean } \\
\text { Square }\end{array}$ & $\begin{array}{l}\text { Source of } \\
\text { Variation }\end{array}$ & $\begin{array}{l}\text { Mean } \\
\text { Square }\end{array}$ & F \\
\hline 173.169 & 3 & 57.723 & $R X I X D X A$ & 6.266 & - \\
\hline 191.967 & 6 & 31.994 & $S X R X I X A$ & 24.255 & - \\
\hline 264.641 & 9 & 29.404 & $S X R X D X A$ & 70.975 & 2.41 \\
\hline 477.565 & 12 & 39.797 & $S X D X I X A$ & 13.143 & - \\
\hline 490.708 & 13 & 37.747 & $S X R X D X I$ & 22.225 & - \\
\hline 557.383 & 16 & 34.836 & $D X I X A$ & 37.515 & 1.08 \\
\hline 594.898 & 17 & 34.994 & $R \times I X A$ & 16.890 & - \\
\hline 645.569 & 20 & 32.278 & $R \times D X A$ & 89.057 & 2.75 \\
\hline 912.740 & 23 & 39.684 & $R X D X I$ & 60.223 & 1.52 \\
\hline 1093.410 & 26 & 42.054 & $S \mathrm{X} I \mathrm{XA}$ & 54.389 & 1.29 \\
\hline 1147.799 & 27 & 42.511 & $S X D X A$ & 21.389 & - \\
\hline 1169.188 & 28 & 41.757 & $S X D X I$ & 185.638 & \\
\hline 1169.188 & 28 & 41.757 & $S X R X A$ & 43.098 & 1.03 \\
\hline 1298.483 & 31 & 41.886 & $S X R X I$ & 21.473 & - \\
\hline 1362.903 & 34 & 40.086 & $S X R X D$ & 53.057 & 1.32 \\
\hline 1522.073 & 37 & 41.137 & I X A & 11.391 & - \\
\hline 1533.464 & 38 & 40.354 & D X A & 2.641 & - \\
\hline 1536.105 & 39 & $\begin{array}{l}39.387 \\
\text { (continued) }\end{array}$ & $D X I$ & 19.142 & - \\
\hline
\end{tabular}


Table A - (continued)

\begin{tabular}{|c|c|c|c|c|c|c|}
\hline$+D X I$ & 1555.247 & 40 & 38.881 & $\mathrm{R} \times \mathrm{A}$ & 90.724 & 2.33 \\
\hline$+\mathrm{R} \times \mathrm{A}$, & 1827.420 & 43 & 42.498 & $R \times I$ & 53.183 & 1.25 \\
\hline$+R \times I$ & 1986.968 & 46 & 43.195 & $R \times D$ & 45.683 & 1.06 \\
\hline$+R \times D$ & 2124.016 & 49 & 43.347 & $S \times A$ & 47.267 & 1.09 \\
\hline$+S X A$ & 2171.283 & 50 & 43.426 & $S X I$ & 5.642 & - \\
\hline$+S X I$ & 2176.925 & 51 & 42.685 & $S \times D$ & 92.642 & 2.17 \\
\hline$+S \times D$ & 2269.567 & 52 & 43.646 & $S \times R$ & 11.516 & - \\
\hline$+S X R$ & 2304.115 & 55 & 41.893 & A & 87.890 & 2.10 \\
\hline & 2304.115 & 55 & 41.893 & $I$ & 396.015 & 9.43 \\
\hline & 2304.115 & 55 & 41.893 & D & 78.765 & 1.88 \\
\hline & 2304.175 & 55 & 41.893 & $\mathrm{R}$ & 44.099 & 1.05 \\
\hline is & 2304.115 & 55 & 41.893 & s & 37.515 & - \\
\hline
\end{tabular}

* Significant higher order mean squares eliminated from the error term.

* Significant at the 5 per cent level.

*** Significant at the I per cent Ievel.

**** $S=$ SEX; $R=$ REST; $D=$ Drawings; I= Instructions; $A=$ Activities. 
TABLE B. The Analysis of the Variance of the Number of Reversals on Reversible Figures on Trial 1.

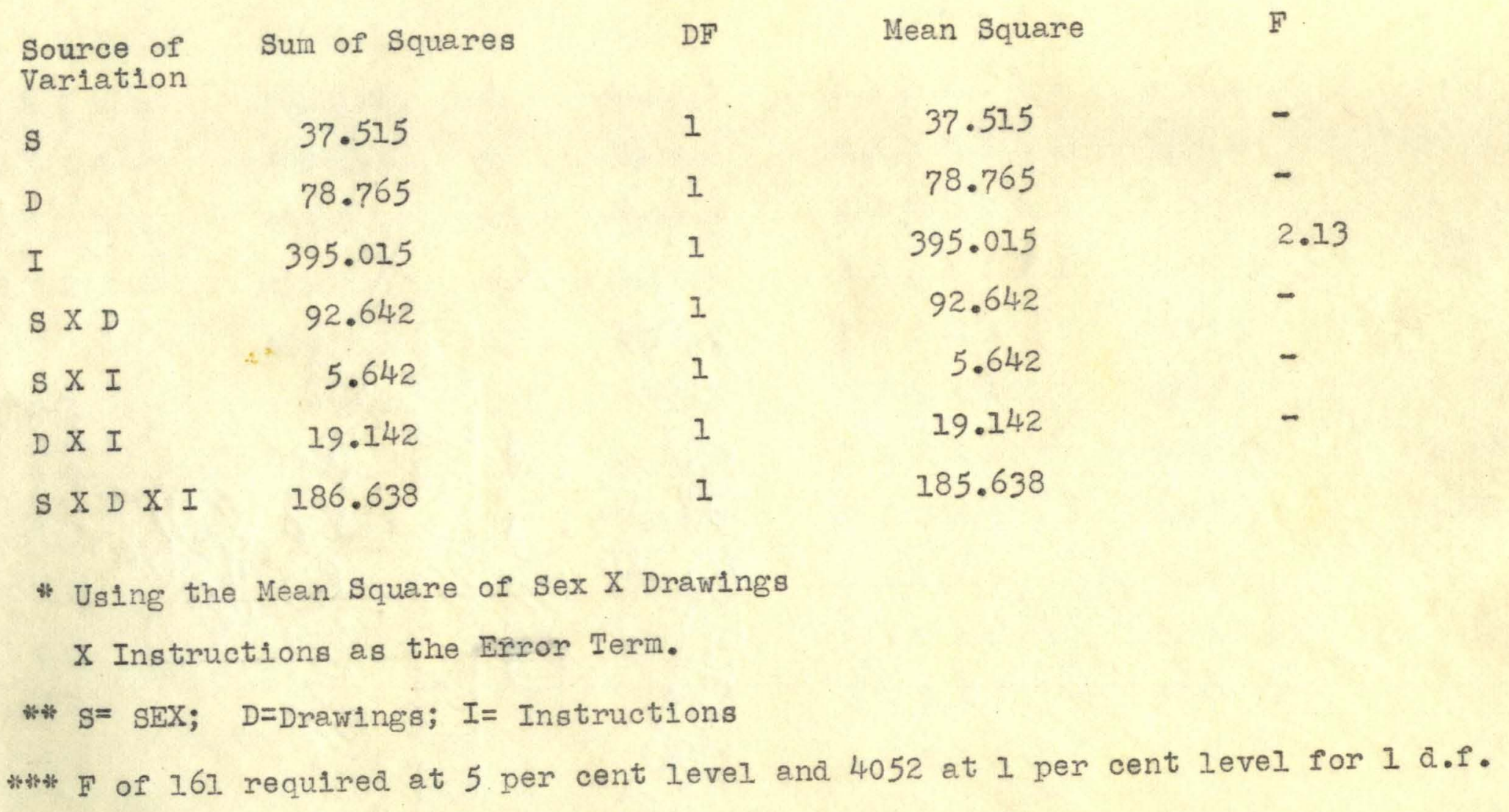


Error Term*

(Poolea Higher)

Orcier Interaction

$S X R X D X I X A$

$+\mathrm{RXDXIXA}$

$+S X R X I X A$

+ SX D X I A

$+S X R X D X A$

+ D X IXA

$+R X I X A$

$+\mathrm{RXDXA}$

+ RX D X I

$+\mathrm{SXIXA}$

$+S$ X D A

$+S \mathrm{XX} I$

$+\mathrm{S} X \mathrm{XA}$

+ S X R X I

$+\mathrm{SXRXD}$

$+I X A$

+ D X A

\section{Sum}

of

Squares

$\pm 7586.13$

25111.9

6

45621 .

49449 .?

63932.

63932.3

65096.6

76522.3

96353.0

115029.5

$115454.9 \quad 24$

$127637.5 \quad 25$

$138479.4 \quad 26$

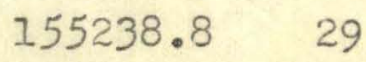

$178380.6 \quad 32$

$197410.7 \quad 35$

$206270.3 \quad 36$

$217532.9 \quad 37$

217532.9
Mean

square

5862.0

4185.3

5069.0

4945.0

4917.9

4917.9

4649.8

4501.3

4817.6

5001.3

4810.6

5105.5

5326.1

5353.1

5574.4

5640.3

5729.7

5879.3

5879.3
Source of

Variation

Mean

Square

R X D X IX A 2508.6

S X R X IX A 6836.4

1.63

S X D X IX A 3828.6

SXRX D A 4827.5

S X R X D I 25829.9

$\mathrm{D} X I X \mathrm{~A}$

$1164 \cdot 3$

$\mathrm{R} X I \mathrm{X} \mathrm{A}$

$\mathrm{RXDXA}$

$R \times D X I$

$\mathrm{S} X I X \mathrm{~A}$

$\mathrm{S} X \mathrm{DX}$

$S$ X D X I

$S \times R X A$

$S X R X I$

$S X R X$

I X A

D X A

D X I

R X A
3808.6

6610.2

6225.5

425.4

12182.6

2.53

10841.9

2.12

5586.5

1.05

7713.9

1.44

6343.4

1.14

8859.6

1.57

11262.6

1.96

***

120322.4

20.46

2.81 
TABLE C - Continued.

\begin{tabular}{|c|c|c|c|c|c|c|}
\hline $\mathrm{R} X \mathrm{~A}$ & 267148.0 & 40 & 6678.7 & $R X I$ & 16936.1 & 2.54 \\
\hline$R \times I$ & 317965.2 & 43 & 7394.3 & $R \times D$ & 5874.4 & - \\
\hline$R X D$ & 335579.5 & 46 & 7295.2 & $\mathrm{~S} X \mathrm{~A}$ & 3038.8 & - \\
\hline$S X A$ & 338618.3 & 47 & 7204.6 & $S X I$ & 4573.2 & - \\
\hline $\mathrm{S} X I$ & 343191.5 & 48 & 7149.8 & $S X D$ & 14671.3 & 2.05 \\
\hline$S X D$ & 357862.8 & 49 & 7303.3 & $S X R$ & 17973.7 & 2.46 \\
\hline $\mathrm{S} X \mathrm{R}$ & 411783.9 & 52 & 7918.9 & A & 62562.5 & 7.90 \\
\hline & 411783.9 & 52 & 7918.9 & $I$ & 471797.2 & 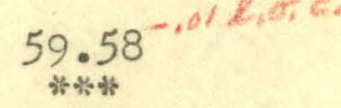 \\
\hline & 411783.9 & 52 & 7918.9 & D & 110473.1 & 13.95 \\
\hline & 411783.9 & 52 & 7918.9 & $R$ & 30233.9 & 3.81 \\
\hline & 411783.9 & 52 & 7918.9 & 8 & 10531.8 & 1.32 \\
\hline
\end{tabular}

* Significant higher order mean squares eliminated from the error term.

** Significant at the 5 per cent level.

*** Significant at the 1 per cent level.

*⿻十⺀㇂ $\mathrm{S}=\mathrm{SEX} ; \mathrm{R}=\mathrm{REST} ; \mathrm{D}=$ Drawing; $\mathrm{I}=$ Instructions; $\mathrm{A}=$ Activities. 
TABLE D. The Analysis of the Variance of The Number of Reversals on Reversible Figures on Trials 6 to $15 . *$

\begin{tabular}{|c|c|c|c|c|}
\hline $\begin{array}{l}\text { Source of } \\
\text { Variation }\end{array}$ & $\begin{array}{l}\text { Sum of } \\
\text { Squares }\end{array}$ & $D f$ & $\begin{array}{l}\text { Mean } \\
\text { Squares }\end{array}$ & $F$ \\
\hline Sex & 10531.8 & $I$ & $10,531.8$ & - \\
\hline Rest & & 3 & $30,233.9$ & 1.17 \\
\hline Drawings & & 1 & $110,473.1$ & 4.28 \\
\hline Instructions & & 1 & $471,797.2$ & 18.27 \\
\hline$S \times R$ & & 3 & $17,973.7$ & - \\
\hline$S \mathrm{X} D$ & & 1 & $14,671.3$ & - \\
\hline$S X I$ & & 1 & $4,573.2$ & - \\
\hline R. X D & & 1 & $5,874.4$ & - \\
\hline$R \times I$ & & 3 & $16,936.1$ & - \\
\hline$D X I$ & & 1 & $12,0322.4$ & - \\
\hline$S \times R \times D$ & & 3 & $6,343.4$ & - \\
\hline$S X R X I$ & & 3 & $7,713.9$ & - \\
\hline$S \mathrm{XDX}$ & & 1 & $10,841.9$ & - \\
\hline$R \times D X I$ & & 3 & $6,225 \cdot 5$ & - \\
\hline$S X R X X I$ & & 3 & $25,829.9$ & - \\
\hline
\end{tabular}
* Using the Mean Square of Sex X Drawings Instructions as the Error
Term.

** $F$ of 10.13 required at 5 per cent level and 34.12 at 1 per cent level for 1 and 3 d. 1 .

*** $S=$ Sex, $R=$ Rest; $D=$ Drawings; I= Instructions. 
TABLE E. The Analysis of the Variance of the Number of Reversals on Reversible Figures on Trial 6 to $15 \%$.

$\begin{array}{lllll}\begin{array}{l}\text { Source of } \\ \text { Variation }\end{array} & \begin{array}{l}\text { Sum of } \\ \text { Squares }\end{array} & \text { Df } & \begin{array}{l}\text { Mean } \\ \text { Squares }\end{array} & F \\ \text { Drawings } & 1 & 110473.1 & - \\ \text { Instructions } & 1 & 471797.2 & 3.92 \\ \text { DXI } & 1 & 120322.4 & -\end{array}$

* Using the Mean Square of Sex X Drawings X Instructions as the error term.

* $D=$ Drawings; $I=$ Instructions.

*** F of 161 Required at 5 per cent level for I d.f. 
TABLE F. SCORES FOR 64 SUBJECTS ON 15 TRIALS

\begin{tabular}{|c|c|c|c|c|c|c|c|c|c|c|c|c|c|c|}
\hline Subject: & 1 & 2 & 3 & 4 & 5 & 6 & 7 & 8 & 9 & 10 & 11 & 12 & 13 & 1.4 \\
\hline 1 & 10 & 15 & 23 & 29 & 26 & 36 & 26 & 22 & 32 & 43 & 52 & 58 & 43 & 49 \\
\hline 2 & 4 & 3 & 5 & 8 & 9 & 7 & 7 & 7 & 6 & 9 & 8 & 11 & 12 & 11 \\
\hline 3 & 5 & 7 & 9 & 6 & 7 & 8 & 9 & 6 & 8 & 9 & 6 & 7 & 8 & 6 \\
\hline 4 & 4 & 3 & 3 & 4 & 2 & 1 & & & 1 & & 7 & 7 & 10 & 15 \\
\hline 5 & 9 & 6 & 9 & 9 & 13 & 12 & 17 & 19 & 17 & 18 & 16 & 16 & 14 & 16 \\
\hline 6 & 5 & 6 & 12 & 3 & 2 & 4 & 4 & 6 & 7 & 5 & $?$ & 3 & 6 & 4 \\
\hline$?$ & 8 & 8 & 8 & 6 & 5 & 6 & 6 & 6 & 4 & 6 & 6 & $?$ & 5 & 8 \\
\hline 8 & 13 & 11 & 9 & 11 & 10 & 12 & 15 & 14 & 14 & 11 & 16 & 16 & 17 & 16 \\
\hline 9 & 6 & 6 & 7 & 6 & 7 & 11 & 13 & 11 & 8 & 9 & 10 & 11 & 12 & 12 \\
\hline 10 & 6 & 5 & 8 & 9 & 9 & 7 & 6 & 7 & 12 & 10 & 7 & 7 & 8 & 8 \\
\hline 11 & 1 & 8 & 5 & 4 & 2 & 2 & 3 & 2 & 4 & 5 & 2 & 2 & $I$ & 2 \\
\hline 12 & 3 & 7 & 7 & 6 & 8 & 10 & 12 & 16 & 16 & 12 & 15 & 15 & 12 & 15 \\
\hline 13 & 1 & 1 & 2 & 2 & 2 & 3 & 3 & 1 & 3 & 3 & 4 & 3 & 6 & 4 \\
\hline 14 & 3 & & 1 & & & 1 & & 2 & & & 3 & $I$ & 1 & 2 \\
\hline 15 & 3 & 7 & 6 & 8 & 10 & 11 & 10 & 11 & 11 & 12 & 12 & 13 & 12 & 14 \\
\hline 16 & 2 & 2 & 12 & 19 & 24 & 34 & 41 & 41 & 47 & 49 & 54 & 51 & 53 & 52 \\
\hline 17 & 7 & 5 & 7 & 6 & 6 & 5 & 6 & 4 & 4 & 4 & 4 & 4 & 3 & 5 \\
\hline 18 & 2 & 8 & 10 & 6 & 8 & 7 & 7 & 7 & 7 & 5 & 6 & 6 & 6 & 5 \\
\hline 19 & 1 & 1 & 2 & 1 & 1 & 1 & 1 & 1 & $I$ & 2 & 1 & & 1 & 1 \\
\hline
\end{tabular}


TABIE F. (Continued)

\begin{tabular}{|c|c|c|c|c|c|c|c|c|c|c|c|c|c|}
\hline 19 & 24 & 33 & 24 & 27 & 29 & 35 & 24 & 26 & 17 & 15 & 19 & 14 & 12 \\
\hline 21 & 8 & 6 & 7 & 9 & 8 & 6 & 6 & 5 & 6 & 6 & 6 & 7 & 6 \\
\hline$I$ & 2 & 6 & 10 & 10 & 15 & 17 & 19 & 21 & 22 & 16 & 18 & 21 & 20 \\
\hline 23 & 3 & 4 & 4 & 7 & 5 & 4 & 5 & 5 & 5 & 2 & 3 & 3 & 3 \\
\hline 10 & 12 & 9 & 6 & 18 & 16 & 21 & 19 & 20 & 23 & 22 & 25 & 24 & 25 \\
\hline 5 & 8 & 8 & $9^{\circ}$ & 9 & 8 & 8 & 8 & 9 & 11 & 19 & 19 & 16 & 17 \\
\hline 5 & 9 & 12 & 12 & 14 & 15 & 13 & 14 & 14 & 13 & 17 & 16 & 16 & 17 \\
\hline 27 & 22 & 15 & 12 & 11 & 14 & 11 & 19 & 19 & 26 & 13 & 23 & 23 & 23 \\
\hline 6 & 5 & 5 & 2 & 1 & 3 & 2 & 1 & 3 & 3 & 1 & $I$ & 1 & \\
\hline 7 & & & & & & & & & & & & & \\
\hline 30 & 8 & 7 & 3 & 5 & 7 & 6 & 5 & 5 & 7 & 7 & 9 & 8 & 8 \\
\hline 11 & 18 & 28 & 52 & 36 & 41 & 67 & 74 & 64 & 52 & 70 & 65 & 66 & 65 \\
\hline 2 & 6 & 3 & 2 & 2 & & 3 & 1 & & & 1 & 1 & 2 & 1 \\
\hline 22 & 17 & 11 & 18 & 29 & 33 & 33 & 33 & 32 & 30 & 30 & 33 & 32 & 37 \\
\hline 7 & 8 & 9 & 8 & 2 & 5 & 5 & 4 & 4 & 11 & 17 & 17 & 11 & 18 \\
\hline 35 & 4 & 5 & 6 & 6 & 4 & 3 & 3 & 8 & 6 & 4 & 3 & 5 & 6 \\
\hline 3 & 4 & 9 & 10 & 10 & 4 & 3 & 3 & 1 & 4 & 3 & 3 & 3 & 4 \\
\hline 5 & 4 & 4 & 7 & 11 & 6 & 6 & 3 & 4 & 5 & 8 & 13 & 10 & 12 \\
\hline 7 & 10 & 9 & 9 & 10 & 10 & 12 & 10 & 10 & 10 & 11 & 12 & 9 & 10 \\
\hline 5 & 10 & 11 & 17 & 25 & 17 & 8 & 12 & 16 & 20 & 23 & 28 & 24 & 28 \\
\hline
\end{tabular}


TABLE F. SCORES FOR 64 SUBJECTS ON 15 TRIALS.

Subject:

\begin{tabular}{|c|c|c|c|c|c|c|c|c|c|c|c|c|c|c|}
\hline 40 & 2 & 6 & 5 & 7 & 8 & 8 & 8 & 10 & 11 & 8 & 9 & 9 & 7 & 10 \\
\hline 41 & 9 & 11 & 10 & 9 & 6 & 6 & 6 & 7 & 5 & 6 & 6 & 6 & 6 & 5 \\
\hline 42 & 4 & 12 & 12 & 16 & 14 & 7 & 10 & 8 & 6 & 7 & 9 & 8 & 8 & 8 \\
\hline 43 & 24 & 222 & 22 & 25 & 20 & 19 & 20 & 21 & 25 & 23 & 33 & 30 & 29 & 28 \\
\hline 44 & 22 & 25 & 27 & 31 & 30 & 30 & 27 & 25 & 26 & 26 & 26 & 25 & 19 & 30 \\
\hline 45 & $I$ & 3 & 5 & 1 & 2 & 1 & 1 & 1 & 1 & 1 & & 1 & & $I$ \\
\hline 46 & 9 & 13 & 26 & 40 & 50 & 60 & 37 & 36 & 28 & 26 & 23 & 26 & 5 & 11 \\
\hline 47 & 9 & 26 & 22 & 27 & 33 & 45 & 48 & 56 & 56 & 54 & 50 & 52 & 49 & 47 \\
\hline 48 & 10 & 14 & 16 & 16 & 14 & 18 & 14 & 19 & 20 & 15 & 12 & 10 & 15 & 14 \\
\hline 49 & 4 & 5 & 7 & 7 & 14 & 8 & 7 & 8 & 9 & 7 & 8 & 9 & 10 & 9 \\
\hline 50 & 6 & 8 & 6 & 4 & 6 & 4 & 6 & 5 & 5 & 6 & 5 & 4 & 5 & 5 \\
\hline 51 & 26 & 35 & 35 & 34 & 37 & 46 & 42 & 46 & 51 & 58 & 54 & 62 & 62 & 70 \\
\hline 52 & 9 & 12 & 10 & 15 & 17 & 14 & 15 & 16 & 19 & $2 I$ & 26 & 22 & 23 & 25 \\
\hline 53 & 9 & 4 & 10 & 12 & 11 & 14 & 15 & 12 & 8 & 11 & 14 & 8 & 12 & 15 \\
\hline 54 & 42 & 42 & 40 & 31 & 33 & 33 & 40 & 34 & 34 & 38 & 34 & 31 & 27 & 33 \\
\hline 55 & 5 & 13 & 10 & 7 & 7 & 5 & 6 & 4 & 3 & 5 & 5 & 7 & 8 & 6 \\
\hline 56 & 1 & 4 & 4 & 4 & 2 & 2 & 2 & 2 & 2 & 4 & 2 & 3 & 3 & 3 \\
\hline 57 & 11 & 4 & 4 & .14 & 14 & 15 & 14 & 9 & 7 & 5 & 18 & 20 & 12 & 11 \\
\hline 58 & 8 & 14 & 10 & 6 & 2 & 4 & $\begin{array}{r}4 \\
100\end{array}$ & 6 & 6 & 4 & 4 & 4 & 6 & 8 \\
\hline
\end{tabular}


TABLE F. SCORES FOR 64 SUBJECTS ON 15 TRIALS (Continued)

$\begin{array}{rrrrrrrrrrrrrrrr}59 & 10 & 16 & 17 & 15 & 14 & 17 & 12 & 15 & 19 & 17 & 7 & 14 & 12 & 14 & 11 \\ 60 & 13 & 28 & 25 & 33 & 30 & 29 & 32 & 34 & 34 & 35 & 34 & 32 & 33 & 35 & 35 \\ 61 & 14 & 29 & 28 & 36 & 39 & 44 & 48 & 50 & 42 & 44 & 58 & 62 & 50 & 54 & 53 \\ 62 & 6 & 7 & 8 & 6 & 6 & 7 & 7 & 7 & 6 & 7 & 12 & 11 & 11 & 11 & 10 \\ 63 & 2 & 1 & & 1 & 1 & & 1 & 2 & 3 & 2 & 4 & 6 & 4 & 6 & 7 \\ 64 & 5 & 6 & 10 & 1 & 2 & 1 & 6 & 2 & 5 & 3 & 4 & 3 & 4 & 3 & 3\end{array}$




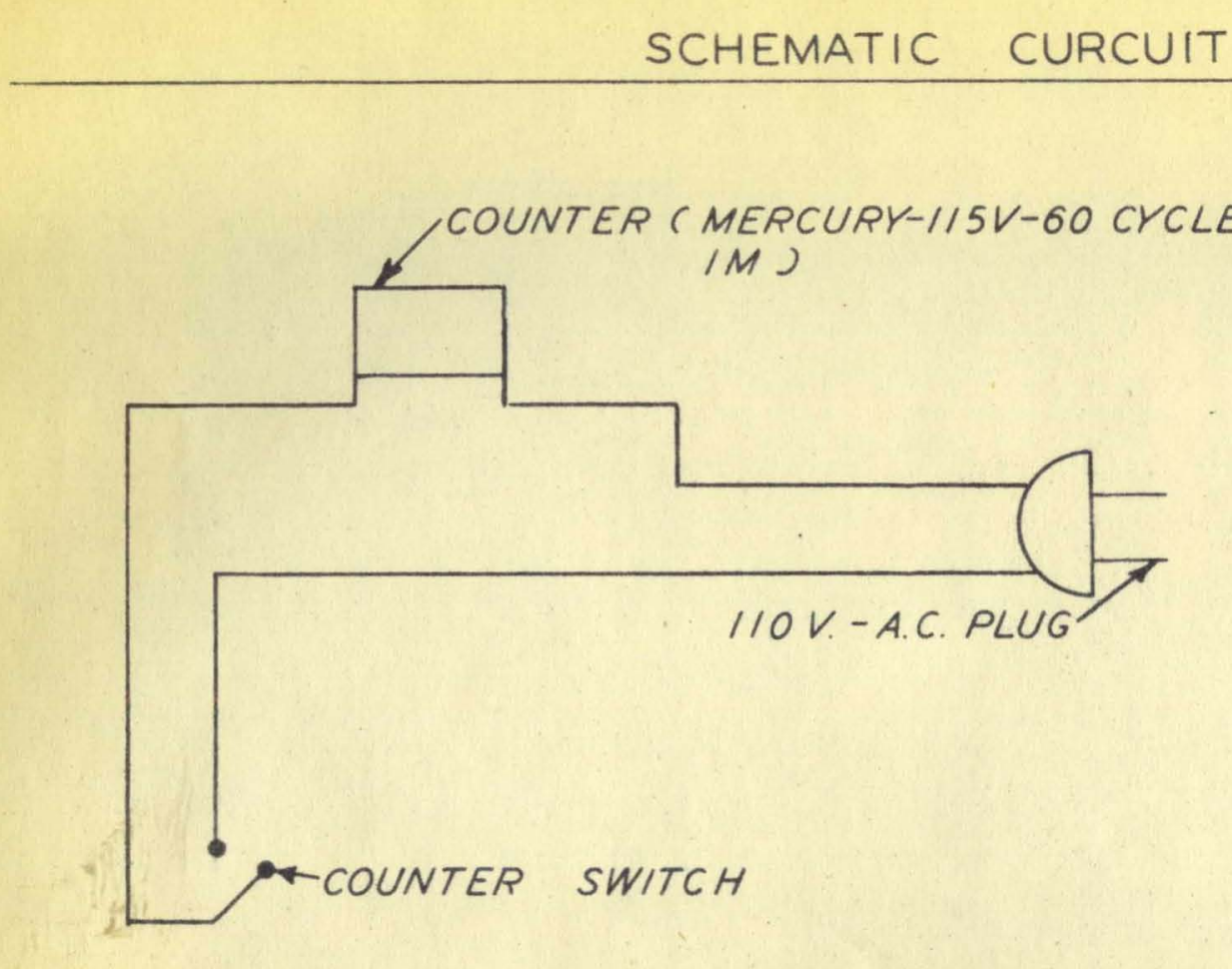

DRAWING FOR APPARATUS

COUNTER CIRCUIT

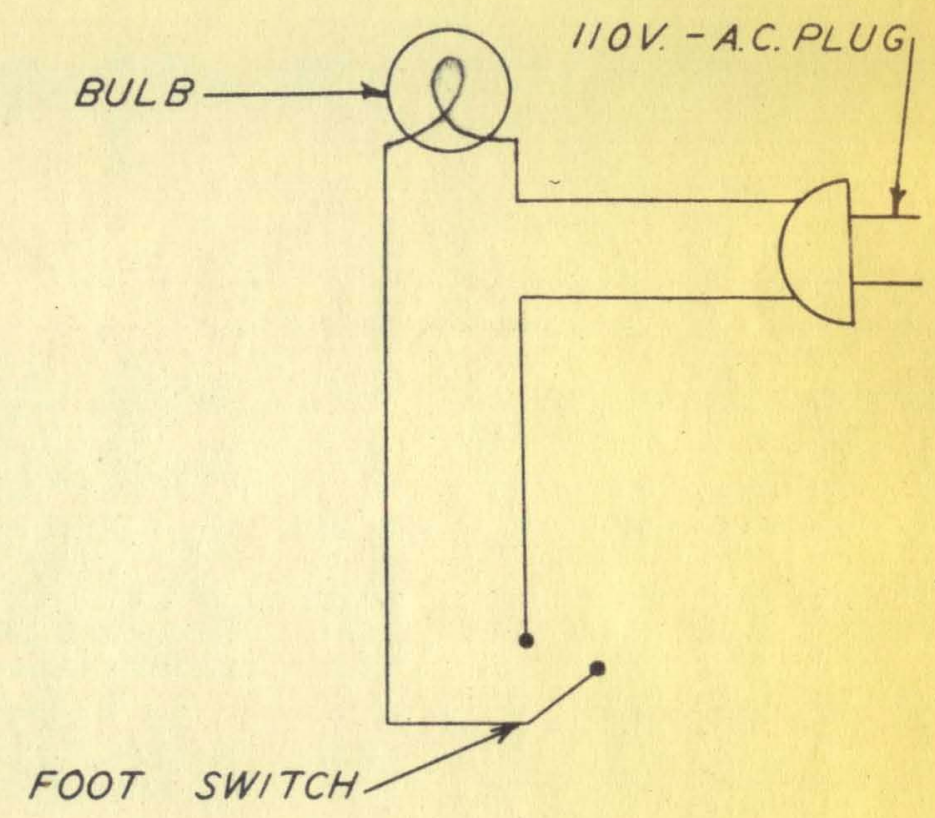

LIGHT CIRCUIT 
1. Bender, L. A V1suel lotor Gestalt qest and Its alinical. Ilse. Res. Monoer. Aner. Orthopsrohist. Agan... No. 3, 1948 ,

2. Birls, A. G. Blocking: A Nev Princlple of Mental Fatigue. Amer. I. Pavoholes.

3. Bonser, F.0. A study of the Relations Between Mental Activity and the Ciroulation of Blood. Esyohol. Rev. 1903, 10,120-138.

4. Bruner, J.S., Postman, L., and Mosteller, F. A Note on the Mea surements of Revergals of Perspective. Zaxchonetrike, 1950 , 15. $63-72$.

5. Donahus, T. $3 .$, and Griffltts, C.I. The Inrluenes of Complex1ty on the Fluotuations of the IIlusion of Reversibie Perspeot1ve. Amer. I. Paychol, 1931. 43, 613-617.

6. Bawards, Allen L. Experimental Design in Psychologleal Researoh, New York, Rinehart \& Co., 1950.

7. Flugel, J.0. The Influence of Attention $1 \mathrm{n}$ Illuglone of Revergibie Perspeotive. Brit. Bavchol. 1912-1913, v5, 357-397,

8. Fluge1, J.0. Some Observation on Locel Fatigue in IIIusions on Reversibie Peropeotive. Batt. J. Pazohol, 1913-1914,

9. George, R.W. The Elgnirteance of the Fluctuatlons Experieneed in observing F1gures and in Blnocular Rivalry. J. gen. Pagehoz. 1936. 15, 39-61,

10. Cordon, Kate. Meaning in Memory and Attention, Parchol.Rev. $1903,10,267-283$.

11. Gullford, J.P., and Brely, K.W. An Expertmental Test of MoDougali's Theory of Bxtroversion-Introversion. I. Abnorm. Pavohol., 1931, 25, 382-389.

12. Harrower, M.R. Changes in Figure-ground Perception in Patients with Cortical Lesions. Extt. I. Zsychol., 1939.

13. Higginson, G.D. A xiew Explanation of some go-called I11usory Patterns. I. Psychol.e. 1936, 1, 295-311.

1h. Hollingwirth, H.I. Perceptual Muetuation as a Fatigue Index. Baychol. Bull., 1938, 35, p. 628.

15. Hunt., J. MeV. \& Guilford, J.P. 1933 Jiuotuation of an Ambitious Plgure in Demtis Prasox and in Vanlo-deptessive Pat1ents. J. Abnorm. Bac. Paxchol., 1933, 27, 443-452. 
16. Personality and the Behavior Disorderd. Nen York: Ronald, 1944.

17. Kohter, Voligang Dynamios in Psychology, Liverurtght PubIlshing Corp., Hev York, 1940.

18. MoDougall, M1211am. The Physlologlcal Factors of the Attention Process MInd. 1906, XV. 329-359.

19. MoDougall, W1112am. The Efrecte of Alcohol and Some other Druga.

20. During Normal and Fat1gued Cond1tlons. Med. Res.Camnc11 Report, 1920, 24-29.

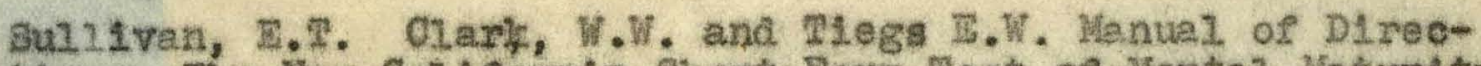
tions- The Neve Callrornia Short-Form Test of Mental Naturity Internediate 147 8-Form, Published by Californla Test Bureau, 5916 Hollywood Boulevard, Los Angelos, 28, California, 1947.

21. Solalder, 2. Pgychto alsturbance AP Aner. L. Parohtat., 1934, 91, 155-188,

22. Sherrington, C.S. The Integra tive Aetion of the Nervous system, Yal. Univeraity Pross, London, 1906.

23. S1aughter, J.W. The Muctuations of Attention in Some of The1r Psychoioglcal, Reiations. Amer. I. of Esyohol., 1901.

24. Nashburn, M.F., ReagIn, C., and Thurston, I. Studies From the Psychologleal Laboratory of Vassar College. The Comparative Controllablitity of the Fiuotuations of Sinple and. Complez Ambleuous Perspective Figures. Aner. I. Bsychoi, $1934,46,636-638$. 